\title{
Evaluating Fungal Mixed Culture for Pretreatment of Cotton Gin Waste to Bioethanol By Enzymatic Hydrolysis and Fermentation Using Co-Culture
}

\author{
Shitarashmi Sahuand, Krishna Pramanik* \\ Department of Biotechnology and Medical Engineering, National Institute of Technology, \\ Rourkela-769008, Orissa, India
}

Received: 2 May 2016

Accepted: 12 August 2016

\begin{abstract}
The prime effort of the present investigation is to release the complex mixtures of cellulose and hemicellulose by delignification of cotton gin waste using a mixed culture of Trametes pubscens and Pycnoporus cinnabarinus. The delignification process was found to be efficient in the release of cellulose and hemicellulose and the pretreated biomass accessed to hydrolysis by producing $\mathrm{C} 6$ sugar. It is further examined that the solid-state cultivation (SSC) achieving $57.5 \%$ of lignin removal was more efficient than the submerged state of cultivation (SMC) with $45.6 \%$ of delignification. The corresponding cellulose and hemicellulose release was measured as 64 and $68.5 \%$ in SSC. The delignification was further confirmed by FTIR, XRD, and SEM analysis of pretreated and untreated cotton gin waste. The pretreatment process was further optimized by a response surface model that achieved $63.2 \%$ delignification in SSC. The enzymatic hydrolysis of delignified waste biomass resulted in $22.06 \mathrm{~g} / 1$ sugar concentration after $48 \mathrm{~h}$. The mixture of glucose and xylose-rich hydrolysates ( $32.17 \mathrm{~g} / 1$ sugars) was fermented with co-culture of the yeast strains Saccharomyces cerevisiae and P. stipitisstrains, which resulted in $13.05 \mathrm{~g} / 1$ ethanol concentration with $0.40 \mathrm{~g} / \mathrm{g}$ ethanol yield after $64 \mathrm{~h}$. Thus it has been demonstrated that the delignification of cotton gin waste using mixed culture and fermentation using co-culture of yeast strains was efficient for bioethanol production.
\end{abstract}

Keywords: cotton gin waste, mixed culture of white rot fungi, pretreatment, hydrolysis, co-culture fermentation

*e-mail: kpr@nitrkl.ac.in 


\section{Introduction}

Throughout the world, a huge quantity of cotton gin waste $(\mathrm{CGW})$ is generated by cotton mills. Due to environmental pollution, disposal of this waste is one of the biggest problems faced by the cotton industry. In recent years, efforts have been put in place to produce bioethanol from lignocellulose biomass rather than energy crops because of the rise in food prices and consumption of land and water for their growth [1]. Globally, India is the second largest cotton producing country and it produces an enormous amount of cotton gin waste annually [2]. Cotton gin waste is one of the potential sources of lignocellulosic biomass, because of its availability, sustainability, and cost effectiveness [2]. The raw cotton processing unit generates cotton gin residue (CGR), which contains immature bolls, cotton seed, hulls, burs, sticks, leaves, cotton lint, and dirt [1]. Worldwide production of this waste is approximately 3.23 million tons per year [3]. Therefore, these wastes can be utilized as a promising source for the production of bioethanol. The prime ingredients of cotton gin waste are cellulose, which binds tightly with lignin and hemicellulose to form complex materials, hence pretreatment is a vital step for releasing cellulose and hemicellulose for their further conversion into sugar and, subsequently, ethanol [4].

Existing pretreatment methods have largely been developed on the basis of physicochemical conversions such as steam explosion, dilute acid, alkali, and oxidation [5-6], but these processes have several disadvantages, such as the required high temperature, pressure, and energy for their analysis, and the toxic by-product and corrosion effect [7-8]. In contrast, fungal pretreatment utilizes their enzyme systems to degrade the lignin and hemicellulose component of lignocellulosic biomass with comparatively low energy requirement, minimal toxicbyproduct formation, the absence of substrate loss due to chemical modification, and mild environmental conditions $[7,9]$. Most of themixed cultures of white rot fungi were reported for biodegradation in producing high activity enzymes due to their synergistic actions [10-11]. Mixed fungal cultures could lead to higher enzyme production through synergistic interactions, but the final results seem to depend on several factors such as particular species combinations or modes of interaction among species, and micro-environmental or nutritional conditions in the substrate under colonization [12].

Hence the present study explored the efficiency of fungal mixed cultures toward pretreatment of cotton gin waste through solid and submerged cultivation (SSC and $\mathrm{SMC})$. The present investigation focuses on optimizing pretreatment conditions using solid state cultivation through a response surface model (RSM) based on central composite design (CCD). The untreated and pretreated biomass were assessed by FTIR, XRD and SEM analysis for qualitative determination of the structural and morphological changes indicating the delignification of cotton gin waste. The study highlights the efficient delignification of cotton gin waste using white rot fungi followed by cellulose hydrolysis using a commercial enzyme to produce C6 sugars. An attempt has also been made to get a higher release of C5 sugar from delignified waste biomass by acid treatment. Furthermore, the fermentation of reduced C6 and C5 sugars was carried out by the most widely used yeast strains - Saccharomyces cerevisiae (C6) and Pichia stipitis (C5) - to produce bioethanol [13-14].

\section{Materials and Methods}

\section{Biomass Collection and Preparation}

Cotton gin waste was collected from Shree Ambica Agro Industries Ltd., Balangir, Orissa, India. The cotton fiber of the waste was reduced in length using grinding and milling by a pulverisette- 5 milling machine. The impurities were removed by washing with water and dried overnight in an oven at $60^{\circ} \mathrm{C}$.

\section{Microorganisms}

The white rot fungal strains Trametes pubscens (NCIM No. 1087) and Pycnoporus cinnabarinus (NCIM No. 1181) were collected from the National Collection of Industrial Microorganisms in Pune, India. Fungal strains were maintained by inoculation on potato dextrose agar (PDA) plates and kept for incubation (4-5 days) at $35^{\circ} \mathrm{C}$. The fresh strains were finally stored at $4^{\circ} \mathrm{C}$ for further use. The most commonly studied yeast Saccharomyces cervisiae (NCIM No. 3090) and Pichia stipitis (NCIM No. 3498) were selected for the fermentation of hydrolysed sugars. S. cerevisiae inoculum was developed for fermentation by growing the cells at $30^{\circ} \mathrm{C}$ for $24 \mathrm{~h}$ in a culture medium containing $(\mathrm{g} / \mathrm{l})$ : dextrose, 30.0 ; yeast extract, 3.0; peptone, 5.0; $\left(\mathrm{NH}_{4}\right) 2 \mathrm{HPO}_{4}, 0.25$; and $\mathrm{pH}$ $6.0 \pm 0.2$ [15]. The P. stipitis inoculum was prepared using $(\mathrm{g} / \mathrm{l})$ : xylose, 50.0; yeast extract, 3.0; malt extract, 3.0; peptone, 5.0; and $\mathrm{pH} 5.0 \pm 0.2$ and $30^{\circ} \mathrm{C}$. Cells were grown until an optical density (OD-600) of 0.6 was achieved [15].

\section{Composition Analysis of Cotton Gin Waste}

The composition of cotton gin waste was analyzed for moisture, ash, lignin, hemicellulose, and cellulose contents. The biomass was consecutively extracted with an alcohol-benzene $(1: 2 \mathrm{v} / \mathrm{v})$ mixture. The carbohydrate and other extractives present in cotton gin waste were estimated by following the TAPPI protocol [16].

\section{Pretreatment of Cotton Gin Waste}

The fungal pretreatment of cotton gin waste was carried out by submerged (SMC) and solid state (SSC) cultivation. In SMC pretreatment, $6 \mathrm{~g}$ air-dried cotton 
waste was added with $108 \mathrm{ml}$ acetate buffer $(20 \mathrm{mM}$, $\mathrm{pH} 4.5$ ) and $1 \mathrm{ml}$ spore inoculum of mixed culture. In solid state cultivation, $6 \mathrm{~g}$ waste was mixed with $9.6 \mathrm{ml}$ acetate buffer and $6 \mathrm{ml}$ spore inoculums to obtain $75 \%$ substrate moisture content. The pretreatment experiments were carried out in $250 \mathrm{ml}$ Erlenmeyer flasks capped with a silicon stopper with inlet and exit lines connected to $0.2 \mu \mathrm{m}$ filters. A sample without fungal strain was used as acontrol. The cotton waste was autoclaved for 20 mins at $121^{\circ} \mathrm{C}$ and $15 \mathrm{psi}$, then treated with acetate buffer and inoculated with spore suspension. Pretreatment was carried out in an air convection incubator at $35^{\circ} \mathrm{C}$ with a shaking speed of $100 \mathrm{rpm}$, and flasks were flushed with oxygen $\left(125 \mathrm{ml} \mathrm{min}^{-1}\right)$ for $10 \mathrm{~min}$ every seven days for 40 days of incubation.

\section{FT-IR, XRD, and SEM Characterization of Cotton Gin Waste}

FT-IR spectra of dried cotton gin waste samples were observed in an FTIR spectrophotometer (Perkin Elmer-Version 5.3). The samples were mixed with $\mathrm{KBr}$ for uniform dispersion and spectra were obtained over the range of $400-4,000 \mathrm{~cm}^{-1}$ with a spectral resolution of $0.5 \mathrm{~cm}^{-1}$.

The overall crystallinity of untreated and pretreated samples was determined by XRD PW 3040 equipment using $\mathrm{Cu} \mathrm{K} \alpha$ radiation $(\alpha=1.54 \AA)$ at $30 \mathrm{kV}$ and $20 \mathrm{~mA}$. The samples were scanned and intensity was observed at $2 \theta$ range from $20^{\circ}$ to $70^{\circ}$ with a scanning speed of $3 \%$ min. Crystalline ( $\%$ ) was calculated as per the formula $\left[\left(\mathrm{I}_{002}-\mathrm{I}_{\mathrm{am}}\right) / \mathrm{I}_{002}\right] \times 100$, where $\mathrm{I}_{002}$ represents maximum crystalline intensity peak at $2 \theta$ between $22^{\circ}$ and $23^{\circ}$ for cellulose $I$ and $I_{a m}$ represents minimum crystalline intensity peak at $2 \theta$ between $18^{\circ}$ and $19^{\circ}$ for cellulose I [12]. SEM images for both untreated and pretreated samples of cotton gin waste were obtained after drying followed by coating with platinum using JEOL JSM6480 LV SEM.

\section{Optimizing Pretreatment Parameters}

The two most efficient fungal strains, namely Trametes pubscens (NCIM No. 1087) and Pycnoporus cinnabarinus (NCIM No. 1181) were screened and used for delignification, which was reported earlier based on the results of cellulose, hemicellulose, and lignin degradation during the pretreatment process of cotton gin waste [1]. A three-level response surface model (RSM) based on central composite design (CCD) was employed for optimizing the pretreatment process using Minitab $16.2 \mathrm{v}$ software, which is the 20 combinations with six center points of three variables [1]. Statistical analysis was performed with $95 \%$ confidence level. Three different parameters with three different levels were selected for this study: (i) $\mathrm{pH}(4,4.5$, and 5), (ii) $\mathrm{rpm}(100,120$, and 140) and (iii) temperature $\left(30,35\right.$ and $\left.40^{\circ} \mathrm{C}\right)$. The experiment for optimizing the pretreatment process was conducted for 35 days with solid state cultivation because it has shown maximum efficiency based on the result of cellulose, hemicellulose, and lignin degradation of cotton waste [1]. The pretreatment experiments were carried out in triplicate form of the experiment. In coded terms, the lowest, central, and highest levels of three variables were $-1,0$ and +1 , respectively. After 35 days of incubation, the total prcentage of delignification was determined for untreated and pretreated cotton gin waste.

\section{Wash and Heat Wash Pre-Hydrolysis Treatments}

The pretreated samples were washed three times with distilled water and autoclaved for $10 \mathrm{~min}\left(121^{\circ} \mathrm{C}\right.$, $15 \mathrm{psi}$ ), followed by washing. These treatments were carried out after 35 days of solid and submerged states of cultivation to remove fungal biomass and proteins as well as inactivating the fungal effect [17].

\section{Acid Treatment of Delignified Biomass for C5 Sugar Release}

The fungal pretreated and untreated biomasses were hydrolyzed at $10 \%(\mathrm{w} / \mathrm{v})$ substrate loading with dilute maleic acid $(500 \mathrm{mM})$ at $130^{\circ} \mathrm{C}$ for $45 \mathrm{~min}$ [18-20]. The hydrolysate was vacuum filtered and analyzed for reducing sugars. After acid hydrolysis, the residual biomass was washed thoroughly to a neutral $\mathrm{pH}$ and dried at $60^{\circ} \mathrm{C}$ in an oven for enzymatic hydrolysis.

\section{Enzymatic Hydrolysis}

The commercial cellulase enzyme from Trichoderma reesei (ATCC 26921) and $\beta$-glucosidase from Aspergillus niger (Novozyme 188) were purchased from SigmaAldrich. The delignified cellulosic residue of cotton gin waste was suspended in $0.05 \mathrm{M}$ citrate phosphate buffer $\left(\mathrm{pH} \mathrm{5.0)}\right.$ at $50^{\circ} \mathrm{C}$ and soaked in a rotary incubator shaker for $2 \mathrm{~h}$. The biomass was further supplemented with cellulase (3 FPU/ml) and $\beta$-glucosidase (Novozyme 188) (9 FPU/ml) and hydrolysis was performed at $50^{\circ} \mathrm{C}$ and $150 \mathrm{rpm}$ for $64 \mathrm{~h}$. Sodium azide $(0.005 \%)$ was added to avoid any microbial contamination and $1.0 \%(\mathrm{v} / \mathrm{v})$ of tween 80 was supplemented for better accessibility of enzymatic action. The samples were collected every $4 \mathrm{~h}$ and analyzed for sugar release. Total reducing sugars were estimated by the DNS method. All the experiments were performed in triplicate, and error bars shown in the results are standard deviations of triplicates. The hydrolysates were analyzed by high-performance liquid chromatography (HPLC) (Agilent Technologies 1260 Infinity) for carbohydrate estimation using an RI detector.

\section{Fermentation}

Maleic acid-treated hydrolysate and enzymatic hydrolysate was supplemented with $2 \mathrm{~g} / 1$ yeast extract, $2 \mathrm{~g} / 1 \mathrm{KH}_{2} \mathrm{PO}_{4}, 0.5 \mathrm{~g} / 1 \mathrm{NH}_{4} \mathrm{Cl}, 0.5 \mathrm{~g} / 1 \mathrm{MgSO}_{4} \cdot 7 \mathrm{H}_{2} \mathrm{O}, 0.25 \mathrm{~g} / 1$ $\left(\mathrm{NH}_{4}\right) 2 \mathrm{HPO}_{4}, 0.1 \mathrm{~g} / 1 \mathrm{FeCl}_{3} \cdot 2 \mathrm{H}_{2} \mathrm{O}$, and $0.1 \mathrm{~g} / 1 \mathrm{CaCl}_{2} \cdot 2 \mathrm{H}_{2} \mathrm{O}$. 
The fermentation experiment was conducted in $500 \mathrm{ml}$ Erlenmeyer flask by adding 10\% inoculums of a high ethanol yielding $S$. Cerevisiae as glucose and $P$. stipitis as xylose-fermenting yeast strains. The fermentation was carried out at $30^{\circ} \mathrm{C}$, pH 5.5 and $120 \mathrm{rpm}$ for $72 \mathrm{~h}$. Samples were analyzed at regular intervals of $8 \mathrm{~h}$ and centrifuged at $10,000 \mathrm{~g}$ at $4^{\circ} \mathrm{C}$ for $15 \mathrm{~min}$. The cell free supernatant was used to determine the ethanol and residual sugar concentration. The ethanol content was determined by gas chromatography (Agilent Technology, USA) with an elite-wax (cross bond-polyethylene glycol) column $(30.0 \mathrm{~m} \times 0.25 \mathrm{~mm})$ at $85^{\circ} \mathrm{C}$, and flame ionization detector (FID) at $200^{\circ} \mathrm{C}$. The ethanol standards were prepared using commercial-grade ethanol (Sigma-Aldrich).

\section{Results and Discussion}

\section{Composition of Cotton Gin Waste}

The chemical composition of cotton gin waste varies depending on the growing location, season, harvesting methods, and analysis procedures [21]. The composition of cotton gin waste was determined as $40.3 \%$ cellulose, $19.8 \%$ lignin, $15 \%$ hemicellulose, $9 \%$ ash, $8.5 \%$ moisture content and $7.4 \%$ other extractives. The high percentage of carbohydrates $(56.3 \%)$ makes the cotton gin waste a potential renewable feedstock for bioethanol production [1].

\section{Fungal Pretreatment of Cotton Gin Waste}

Lignin removal from the cotton gin waste by pretreatment process reveals the crystalline structure of cellulose and improves solubilization, which facilitates substrate accessibility by hydrolytic enzymes [7, 22]. Therefore, an efficient/suitable pretreatment method is employed before performing enzymatic hydrolysis in order to achieve maximum yield of sugar. The pretreatment processusing solid and submerge cultivation removed $57.5 \%$ and $50.6 \%$ lignin, respectively. The corresponding cellulose and hemicellulose reduction were obtained as $64 \%$ and $68.5 \%$ in SSC, whereas their values in SMC were $49.2 \%$ and $56 \%$, respectively. Thus, solid state cultivation with the mixed culture of fungi has shown better pretreatment efficiency than submerged cultivation, which was also reported in earlier studies [23-24]. In an earlier study, P. Chrysosporium and Pycnoporus cinnabarinus individually were successfully used for biological pretreatment of cotton stalks and cotton gin waste without removing cellulose, but the mixed culture of white rot fungi for the pretreatment of cotton gin waste has so far not been investigated [24-25]. The fungal pretreatment has advantages over the non-biological methodology as a higher amount of toxic by-products such as phenol, furfural, and 5-hydroxymethyl furfural (HMF), having an inhibitory effect toward the growth of yeast strains during fermentation that are formed later [13].

\section{Effects of Wash and Heat-Wash Pre-Hydrolysis Treatments}

Lignin derivatives can also be removed from the pretreated material by washing with water [26] or inactivated by heating [24]. Furthermore, it has been reported that washing and heating increase the cellobiose content with improved delignification after and before pretreatment [25]. The lignin removal in solid and submerged cultivation were slightly improved at 58.0\% and $50.9 \%$, respectively, by washing and heating. The corresponding cellulose and hemicellulose released were obtained after heat-wash treatment as $64.1 \%$ and $69 \%$ by SSC, which was higher than SMC. The heat-wash treatment helped to remove the attached fungal mycelia, thereby achieving increased enzyme accessibility to cellulose in pretreated samples.

\section{Optimizing Pretreatment Parameters}

The optimization of experimental factors to maximize delignification was successfully performed as per central composite design (CCD). The optimization study involving three individual parameters such as $\mathrm{pH}$, temperature, and rpm (shaking speed) to obtain the maximum percentage of lignin removal of cotton gin waste. Delignification was obtained in the range of 54 to $63.2 \%$ with optimized conditions. The mathematical equation relating to the percentage of lignin degradation to the different independent variables including interaction effects is shown below in terms of the coded factor:

$$
\begin{gathered}
\mathrm{Y} 1=62.62+0.37 \mathrm{~A}_{1}-0.29 \mathrm{~A}_{2}+0.66 \mathrm{~A}_{3}-3.42 \mathrm{~A}_{1}^{2} \\
-2.52 \mathrm{~A}_{2}^{2}-0.67 \mathrm{~A}_{3}^{2}+0.36 \mathrm{~A}_{1} \mathrm{~A}_{2} \\
-0.78 \mathrm{~A}_{1} \mathrm{~A}_{3}-0.13 \mathrm{~A}_{2} \mathrm{~A}_{3}
\end{gathered}
$$

...where $\mathrm{A}_{1}, \mathrm{~A}_{2}$ and $\mathrm{A}_{3}$ represent $\mathrm{pH}$, temperature, and rpm, respectively, and $\mathrm{Y} 1$ represents the experimental response. The individual action of all three parameters were studied, where the interaction and quadratic effects between the dependent variables were found to be significant from the regression model. Analysis of variance (ANOVA) of the quadratic regression for fungal pretreatment of cotton gin waste is summarized in Table 1. The square and interaction effects between the variables were found to be statistically significant with low P-values, although the square terms from the model show more significance or effect with the highest F-value of 141.89. The regression model for the pretreatment of cotton gin waste has been shown a high F-value of 50.87 and a very low probability value $(<0.001)$, which shows the significance of the model [27]. The quality of the model was evaluated by the coefficient $\mathrm{R}^{2}$ and its statistical significance was determined by an F-test. In the pretreated sample, the $\mathrm{R}^{2}$ value was obtained as 0.9786 , which is close to 1 and represents the model that sufficiently fits the data and thus the robustness of the model is justified [12, 28].

Figs 1(a-c) shows the interaction of three parameters on lignin removal of the pretreated cotton gin waste. 
Table 1. ANOVA analysis of RSM model for enzymatic pretreatment of pretreated cotton gin waste.

\begin{tabular}{|c|c|c|c|c|c|c|}
\hline Source & DF & Seq SS & Adj SS & Adj MS & F & P \\
\hline Regression & 9 & 181.194 & 181.194 & 20.132 & 50.87 & 0.000 \\
\hline Linear & 3 & 6.566 & 6.566 & 2.1887 & 5.53 & 0.017 \\
\hline Square & 3 & 168.465 & 168.465 & 56.1548 & 141.89 & 0.000 \\
\hline Interaction & 3 & 6.164 & 6.164 & 2.0546 & 5.19 & 0.020 \\
\hline Residual Error & 10 & 3.958 & 0.3958 & 0.3958 & & 0.001 \\
\hline Lack-of-Fit & 5 & 3.824 & 3.824 & 0.7649 & 28.68 & \\
\hline Pure Error & 5 & 0.133 & 0.133 & 0.0267 & & \\
\hline Total & 19 & 185.152 & & & & \\
\hline $\mathrm{R}^{2}=97.86 \%$ & & & & & & \\
\hline
\end{tabular}

$\mathrm{DF}=$ degree of freedom, $\mathrm{SS}=$ sum of squares, $\mathrm{MS}=$ mean sum of squares, $\mathrm{F}=$ Fisher's $\mathrm{F}$ value (calculated by dividing the MS owing to the model by that, due to error), $\mathrm{P}=$ probability

Fig. 1a) shows a maximum of $62.9 \%$ lignin removal at constant $\mathrm{pH}$ with a variation in temperature and $\mathrm{rpm}$. The three-dimensional plots show a higherdelignification $(63.2 \%)$ after 35 days of solid-state cultivation as dipicted in Fig. 1b). However, at a constant temperature the interaction between shaking speed and $\mathrm{pH}$ gives the maximum value of delignificationas shown in Fig. 1b). The optimization has been performed with a variation of temperature and $\mathrm{pH}$, whereas $\mathrm{rpm}$ is constant, the result of which is shown in Fig. 1c). From the experimental data, the above statistical model suggests the optimum predicted condition of $\mathrm{pH}$, shaking speed, and temperature as $4.5,122 \mathrm{rpm}$ and $35^{\circ} \mathrm{C}$ respectively, achieving a high percentage of delignification. In order to check the reliability of predicted response, the experiment in triplicate was performed under optimum predicted conditions [29-30].

From this design of experiments, the maximum releases of cellulose and hemicellulose were $64.7 \%$ and $71.02 \%$, whereas the delignification efficiency was $63.2 \%$, which is in good agreement with the predicted value. But before optimizing parameters, the corresponding values of cellulose, hemicellulose, and delignification percentage were $64.1 \%, 69 \%$ and $58 \%$ respectively. Therefore, we conclude that solid state cultivation shows efficient delignification of the cotton gin waste, and a higher delignification efficiency can be achieved after optimizing the process parameters through the response surface model.

\section{FTIR, XRD, and SEM Analysis of Untreated and Pretreated Biomass}

FTIR, XRD, and SEM analyses of untreated and pretreated cotton gin waste were analyzed to access any change in the structure and morphology that might have occurred during pretreatment. The FTIR image Fig. 2a) shows the indicative peaks of cellulose and lignin obtained at $1,700 \mathrm{~cm}^{-1}$ to $1,750 \mathrm{~cm}^{-1}, 1,726$, and $1,512 \mathrm{~cm}^{-1}$ as found a) Surface Plot of \% Delignification vs RPM, Temperature

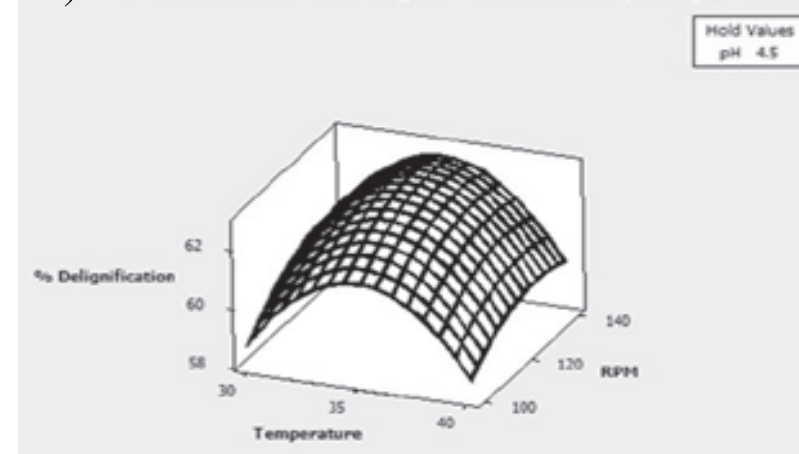

b) Surface Plot of \% Delignification vs RPM, pH

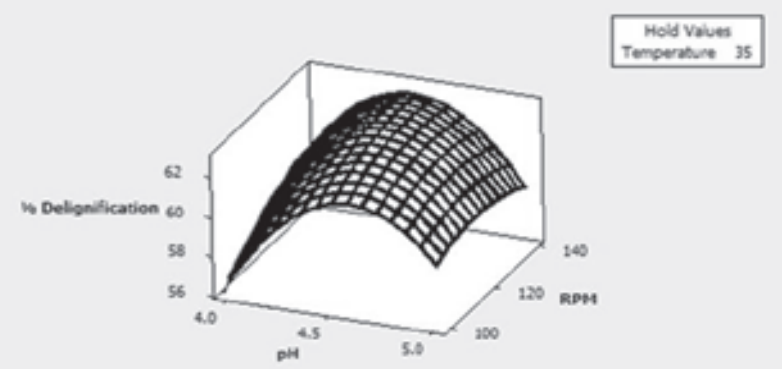

c) Surface Plot of $\%$ Delignification vs Temperature, pH

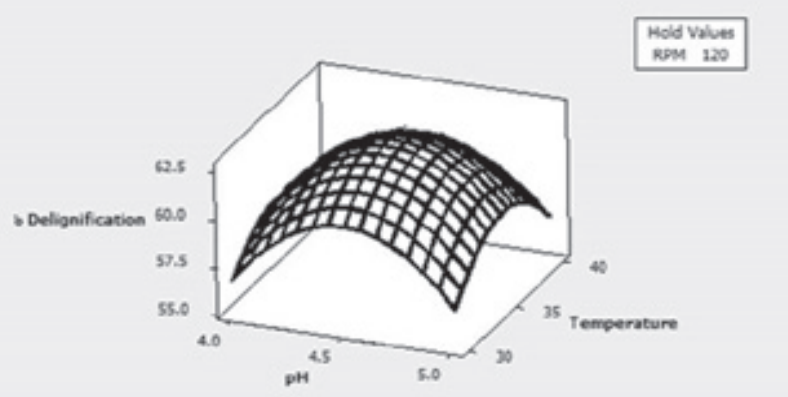

Fig 1. Response surface plots showing the effects of $\mathrm{pH}$ a), temperature b), and RPM c) on the pretreatment of cotton gin waste. 
in the untreated CGW, but not in the pretreated sample [31-32]. This may be due to the reduction of carbonyl $(\mathrm{C}=\mathrm{O})$ compounds such as lignin, some amount of hemicellulose, and other extractives that were removed during pretreatment. The absorption band at $3,393 \mathrm{~cm}^{-1}$ is attributed to the stretching vibrations of hydroxyl $(\mathrm{OH})$ groups in the untreated CGW [12]. Furthermore, a difference in intensity of absorption at $2,500 \mathrm{~cm}^{-1}$ band size was due to the difference in absorbed water content between untreated and pretreated samples. This is explained by a change in the degree of inter molecular H-bonding between $\mathrm{OH}$ group of cellulose and water [1]. It can be expected that there would be an increase in surface area and rearrangement of cellulose microfibrils, which may provide a better accessibility to $\mathrm{OH}$ groups by the enzymes in the pretreated sample as a similar study supports our results [33]. The $\mathrm{OH}$ groups include daliphatic compounds, sorbed water, primary and secondary alcohols found in cellulose, hemicellulose, and carboxylic acids in extractives [1]. Near OH stretching vibrations, $2,900 \mathrm{~cm}^{-1}$ is attributed to $\mathrm{CH}$ stretching vibrations and corresponds to the aliphatic moieties in polysaccharides (cellulose and survived hemicellulose) of the treated sample. The pure cellulosics are obtained at frequencies 1,431, 1,372, 1,318, $1,281,1,165,1,059$ and $897 \mathrm{~cm}^{-1}$ [34].

Cellulose macrofibrils were observed more prominently with increasing pretreatment times Fig. 2b). The XRD analysis of untreated and pretreated samples exhibited similar crystalline patterns. The widths at half height of the peaks at $2 \theta=17^{\circ}$ and $26^{\circ}$ were similar for all samples except for a higher haziness found in the untreated sample and more clarity in the peak of the pretreated sample [32, 34]. The cellulose crystallinity value of an untreated sample of cotton gin waste was $18 \%$, whereas in the pretreated sample it was $25.1 \%$, suggesting the improvement in crystallinity of the biomass due to the removal of lignin and hemicellulose [35]. It is expected that the amorphous region present in-between the regular crystalline region are subjected to an enzyme attack on lignin degradetion during pretreatment.

Scanning electron micrographs (SEM) reveal the surface morphology of biomass (cellulose and hemicellulose fiber) with different severities, as seen in Fig. 2c). The untreated sample shows compact fibers distributed over the whole biomass, whereas the pretreated biomasswas shows partially degraded etched fibers indicating the influence of fungal treatment. This shows an enhancement of surface area due to the removal of lignin and its associated compounds such as hemicellulose. A significant change in the surface property toward favorable interaction with enzymes has occurred due to pretreatment resulting breakage of the amorphous region of cellulose with retention of crystalline fraction [12]. Earlier it was reported that lignin removal from the pretreated sample increases the degree of crystallinity of biomass [33]. The gravimetric analysis shows an amount of $3.9 \%$ biodegradation of biomass occurring by pretreatment using the mixed culture of fungi.
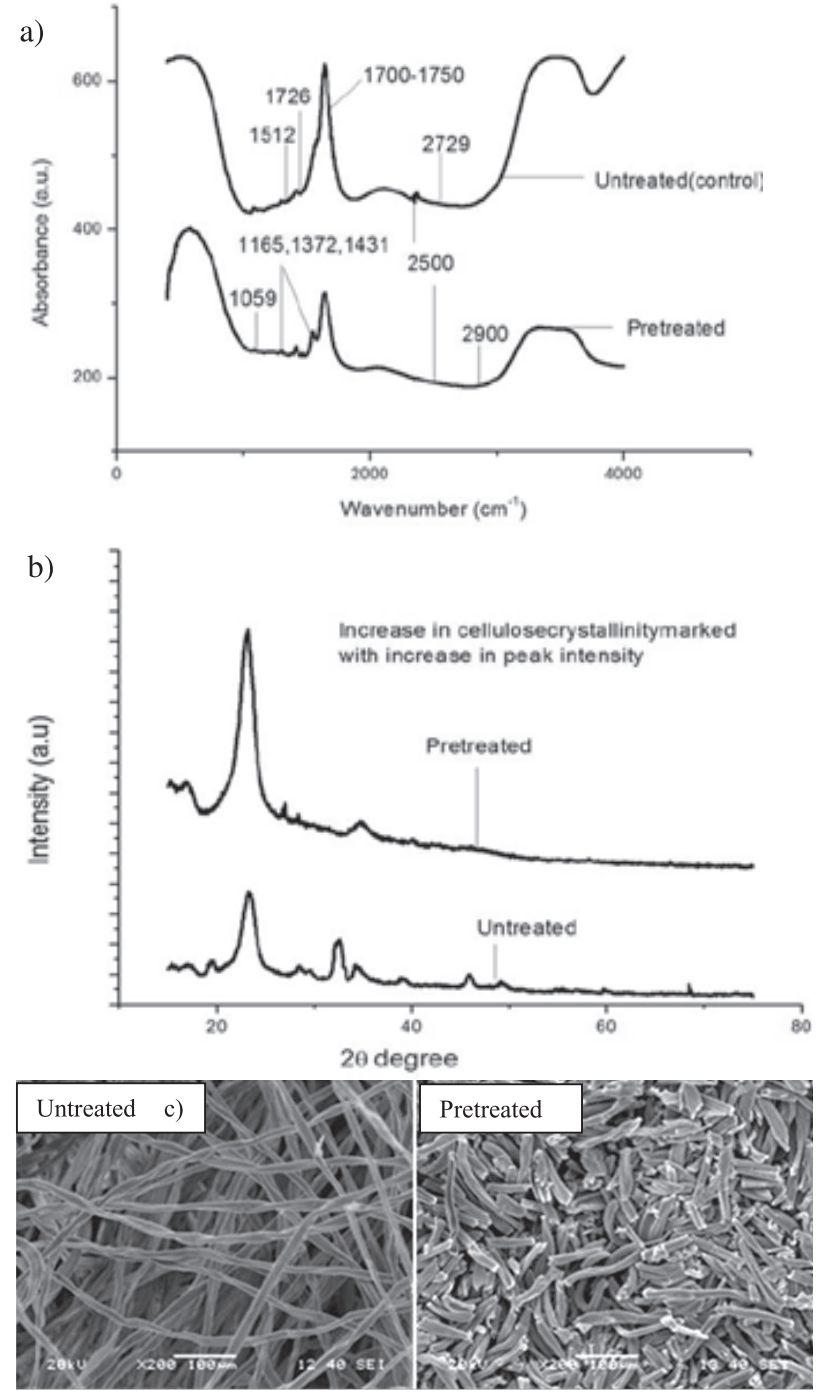

Fig. 2. FTIR a), XRD b), and SEM c) analysis of untreated and pretreated cotton gin waste.

\section{Recovery of Hemicellulose by Maleic Acid Treatment}

The fungal pretreated waste was further treated with maleic acid at $150^{\circ} \mathrm{C}, 45 \mathrm{~min}$, and at $500 \mathrm{Mm}$ concentration. A maximum pentosan sugar yield of $100.15 \pm 0.43 \mathrm{mg} / \mathrm{g}$ was achieved. The corresponding hydrolysate produced was: xylose $(8.04 \pm 0.55)$, glucose $(1.02 \pm 0.63)$ and arabinose $(1.05 \pm 0.45)$.

\section{Enzymatic Hydrolysis of Pretreated Cotton Gin Waste}

Enzymatic hydrolysis hinders the released cellulose of lignocellulosic biomass to be hydrolysed for the fermentation of monomeric sugar [13]. In this study, during enzymatic hydrolysis an efficient increase in sugar concentration was observed until hour 48, at which point prolonged incubation remained almost constant (Fig. 3). However, the maximum saccharification yield of 


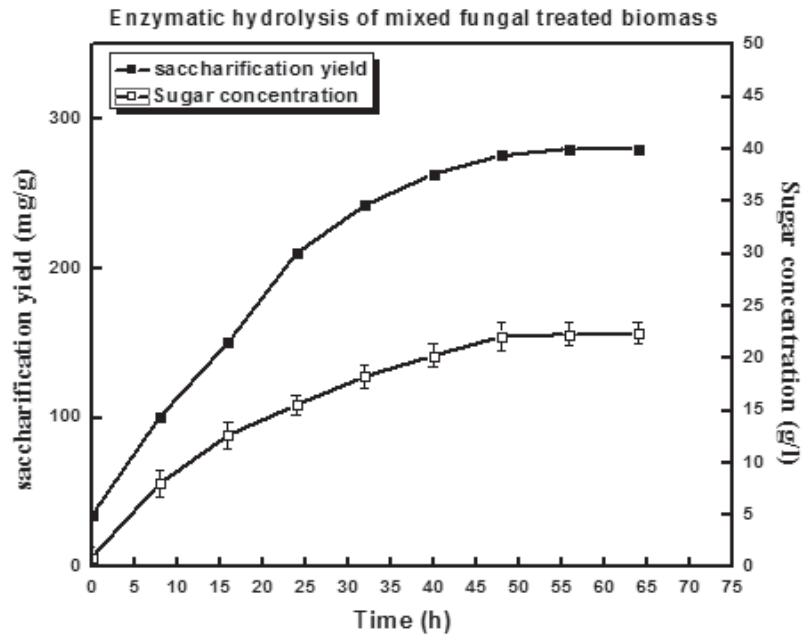

Fig. 3. Enzymatic saccharification of delignified cotton gin waste.

$281.02 \mathrm{mg} / \mathrm{g}$ was achieved after $48 \mathrm{~h}$ and no major change was obtained beyond this period. Moreover, the enzymatic saccharification efficiency of $60.04 \%$ (w/w) was obtained from the extraction of C6 sugar concentration of $22.06 \mathrm{~g} / \mathrm{l}$, which can be compared to other conventional techniques used for the delignification process to enhance the saccharification yield $[3,12]$. The decline in hydrolysis rate after $48 \mathrm{~h}$ could be due to the increasing resistance of the substrate during the period of hydrolysis. End-product inhibition of the enzymes by glucose and cellobiose may also have a major impact on cellulose hydrolysis [3]. In this study, the higher reducing sugar (C6) yield $(281.02 \mathrm{mg} / \mathrm{g})$ and sugar concentration $(22.06 \mathrm{~g} / \mathrm{l})$ were obtained due to enzymatic activity on cellulose of pretreated biomass $[6,13]$. Thus the use of dilute maleic acid treatment after microbial pretreatment shows an improvement in cellulose digestibility of cotton gin waste.

\section{Fermentation}

The mixture of acid (10.11g/l) and enzymatic hydrolysate $(22.06 \mathrm{~g} / \mathrm{l})$ were fermented with a co-culture of $S$. cerevisiae and P. stipitis strains, which resulted in maximum ethanol production of $13.05 \mathrm{~g} / 1$ with $0.40 \mathrm{~g} / \mathrm{g}$ yield and a theoretical yield of $79 \%$ after $64 \mathrm{~h}$ of fermentation, as observed from Table 2 . The reduction in ethanol production after $64 \mathrm{~h}$ of incubation may be due to the consumption of accumulated ethanol by the yeast [3]. When the ethanol starts accumulation in the medium, the yeast population might have consumed simultaneously sugar and ethanol as reported earlier [36]. In the fermentation media the sugar concentration was decreased gradually from $32.17 \mathrm{~g} / 1$ to $2.86 \mathrm{~g} / 1$ with respect to time ( $0 \mathrm{~h}$ to $72 \mathrm{~h}$ ). The corresponding biomass yield was measured at $0.26 \mathrm{~g} / \mathrm{g}$, respectively. The increased yeast biomass could be because of the utilization of the yeast extract present in fermentation medium until $64 \mathrm{~h}$, which was further declined gradually due to the occurrence of the stationary phase of yeast strains [12]. Researchers have reported earlier the percentage of theoretical ethanol yield in the range of 58 to $92.5 \%$, depending on several aspects like season, harvest, and processing protocols [12]. Our studies were supported by Yadav et al. [14], reporting the production of maximum ethanol using co-culture of $S$. cerevisiae and $P$. stipitis produced in comparison with a monoculture of $S$. cerevisiae using acid hydrolysate of rice straw.

\section{Conclusions}

The present work focuses on the utilization of cotton gin waste generated in Indian cotton mills for the production of bioethanol as a future transportation fuel. This study highlights the efficiency of mixed culture of Trametes pubscens and Pycnoporus cinnabarinus white rot fungi toward delignification, thereby achieving

Table 2. Fermentation of acid and enzymatic hydrolysate of cotton gin waste by co-culture of $S$. cerevisiae and $P$. stipitis strains.

\begin{tabular}{|c|c|c|c|c|c|}
\hline Time $(\mathrm{h})$ & $\begin{array}{c}\text { Sugar }(\mathrm{g} / \mathrm{l}) \\
\text { Consumption }\end{array}$ & $\begin{array}{c}\text { Ethanol } \\
\text { conc. }(\mathrm{g} / \mathrm{l})\end{array}$ & $\begin{array}{c}\text { Ethanol } \\
\text { yield }(\mathrm{g} / \mathrm{g})\end{array}$ & $\begin{array}{c}\text { Biomass } \\
\text { conc. }(\mathrm{g} / \mathrm{l})\end{array}$ & $\begin{array}{c}\text { Biomass } \\
\text { yield }(\mathrm{g} / \mathrm{g})\end{array}$ \\
\hline 0 & 32.17 & 0.09 & 0.02 & 0.28 & 0.04 \\
\hline 8 & 21.03 & 5.82 & 0.18 & 3.09 & 0.10 \\
\hline 16 & 16.44 & 7.06 & 0.21 & 3.52 & 0.12 \\
\hline 24 & 11.01 & 10.37 & 0.32 & 5.75 & 0.17 \\
\hline 32 & 8.44 & 11.25 & 0.35 & 6.20 & 0.19 \\
\hline 40 & 6.03 & 12.04 & 0.37 & 6.84 & 0.20 \\
\hline 48 & 4.48 & 12.55 & 0.39 & 7.36 & 0.24 \\
\hline 56 & 3.33 & 12.91 & 0.40 & 7.27 & 0.26 \\
\hline 64 & 3.13 & 13.05 & 0.40 & 0.38 & 0.26 \\
\hline 72 & 2.86 & 12.20 & & 0.25 \\
\hline
\end{tabular}


a high release of cellulose and hemicellulose from cotton gin waste. Furthermore, it was observed that the solid-state fermentation process is more effective in terms of delignification efficiency than submerged fermentation in the pretreatment process. Thus, it has been demonstrated that the use of fungal mixed culture for delignification followed by acid treatment and enzymatic hydrolysis to enhance fermentation using co-culture of yeast strains was not reported earlier, which may pave the way for bioethanol production from cotton gin waste generated in the cotton industry on a large scale, thereby reducing the disposal problem and environmental pollution.

\section{Acknowledgements}

Our research was supported by the Ministry of Environment and Forest, Government of India by sanctioing research project No. 19-14/2007-RE.

\section{References}

1. SAHU S., PRAMANIK K.Delignification of cotton gin waste and its optimization by using white rot fungus Pycnoporus cinnabarinus. Journal of Environmental Biology. 36 (3), 661, 2015a.

2. SAHU S., PRAMANIK K. Bioconversion of Cotton Gin Waste to Bioethanol, Environmental Microbial Biotechnology, Springer International Publishing, Switzerland, 45, 457, 2015b.

3. JEOH T., AGBLEVOR F.A. Characterization and fermentation of steam exploded cotton gin waste, Biomass and Bioenergy., 21 (2), 109, 2001.

4. INGRAM L., ALDRICH H., BORGES A., CAUSEY T., MARTINEZ A., MORALES F. Enteric bacterial catalysts for fuel ethanol production. Biotechnology progress. 15 (5), $855,2008$.

5. CHANDEL A.K., SINGH O.V., CHANDRASEKHAR G., RAO L.V. NARASU M.L. Bioconversion of novel substrate, Saccharum spontaneum, a weedy material into ethanol by Pichia stipitis NCIM3498, Bioresource Technol. 102 (2), 1709, 2011.

6. YANG B., WYMAN C.E. Pretreatment: the key to unlocking low cost cellulosic ethanol. Biofuels BioprBioref. 2 (1), 26, 2008

7. NAZARPOUR F., ABDULLAH D.K., ABDULLAH N., ZAMIRI R. Evaluation of biological pretreatment of rubberwood with white rot fungi for enzymatic hydrolysis. Materials 6 (5), 2059, 2013.

8. LU C., WANG H., LUO Y., GUO L. An efficient system for pre-delignification of gramineous biofuel feedstock in vitro: application of a laccase from Pycnoporus sanguineus H275. Proc Biochem. 45 (7), 1141, 2010.

9. MACHADO K.M., MATHEUS D.R., BONONI V.L. Ligninolytic enzymes production and Remazol Brilliant Blue R decolorization by tropical Brazilian basidiomycetes fungi. Brazilian Journal of Microbiology. 36 (3), 246, 2005.

10. CHI Y., HATAKKA A., MAIJALA P. Can co-culturing of two white-rot fungi increase lignin degradation and the production of lignin-degrading enzymes? Int. Biodeterior. Biodegrad. 59 (1), 32, 2007.
11. PARANI K., EYINI M. Effect of co-fungal treatment on biodegradation of coffee pulp waste in solid state fermentation. Asian J. Exp. Biol. Sci. 1 (2), 352, 2010.

12. KUILA A., MUKHOPADHYAY M., TULI D.K., BANERJEE R. Production of ethanol from lignocellulosics: an enzymatic venture. EXCLI J. 10, 85, 2011.

13. KUHAD R.C., GUPTA R., KHASA Y.P., SINGH A. Bioethanol production from lantanacamara (red sage): pretreatment, saccharification, and fermentation. Bioresource technology. 101 (21), 8348, 2010.

14. YADAV K., SRILEKHA SHAIK NASEERUDDIN G., SAI PRASHANTHI., LANKA SATEESH L., VENKATESWAR RAO. Bioethanol fermentation of concentrated rice straw hydrolysate using co-culture of Saccharomyces cerevisiae and Pichia stipitis. Bioresource technology. 102 (11), 6473, 2011.

15. CHEN Y., STEVENS M.A., ZHU Y., HOLMES J., XU H. Understanding of alkaline pretreatment parameters for corn stover enzymatic Saccharification, Biotechnol Biofuels. 6 (1), 1, 2013.

16. TAPPI, Technical association of pulp and paper industry, Atlanta, Georgia, USA, 1992.

17. HATAKKA A.I. Pretreatment of wheat straw by white-rot fungi for enzymic saccharification of cellulose. European Journal of Applied Microbiology and Biotechnology. 18 (6), 350, 1983.

18. IDREES M., ADNAN A., SHEIKH S., QURESHIC F.A. Optimization of dilute acid pretreatment of water hyacinth biomass for enzymatic hydrolysis and ethanol production. EXCLI journal. 12, 30, 2013.

19. FENG L., QIN L., LIU Z.H., DONG C.Y., LI B.Z., YUAN Y.J. Combined severity during pretreatment chemical and temperature on the saccharification of wheat straw using acids and alkalis of differing strength. BioResources. 9 (1), 24, 2013.

20. KOOTSTRA A.M.J., BEEFTINK H.H., SCOTT E.L., SANDERS J.P. Comparison of dilute mineral and organic acid pretreatment for enzymatic hydrolysis of wheat straw. Biochemical Engineering Journal 46 (2), 126, 2009.

21. KUMARI R., PRAMANIK K. Improved bioethanol production using fusants of Saccharomyces cerevisiae and xylose-fermenting yeasts. Applied biochemistry and biotechnology. 167 (4), 873, 2012.

22. AGBORET V.B., CICEK N., SPARLING R., BERLIN A., LEVIN D.B. Biomass pretreatment: fundamentals toward application. Biotechnology advances 29 (6), 675, 2011.

23. KANCELISTA A., TRIL U., STEMPNIEWICZ R., PIEGZA M., SZCZECH M., WITKOWSKA D. Application of lignocellulosic waste materials for the production and stabilization of Trichoderma biomass. Pol. J. Environ. Stud. 22 (4), 1083, 2013.

24. SHI J., SHARMA-SHIVAPPA R.R., CHINN M., HOWELL N. Effect of microbial pretreatment on enzymatic hydrolysis and fermentation of cotton stalks for ethanol production. Biomass and bioenergy. 33, 88, 2009.

25. SUN Y., CHENG J.Hydrolysis of lignocellulosic materials for ethanol production: a review. J. Bioresourcetechnology. 83, 1-11, 2002.

26. MES-HARTREE M., SADDLER J.N. The nature of inhibitory materials present in pretreated lignocellulosic substrates which inhibit the enzymatic hydrolysis of cellulose. Biotechnology Letters. 5 (8), 531, 1983.

27. LIU Q., CHENG K., ZHANG J., LI J., WANG., Statistical optimization of recycled-paper enzymatic hydrolysis for simultaneous saccharification and fermentation via 
central composite design. J. Applied biochemistry and biotechnology. 160 (2), 604, 2010.

28. PATEL B.P., KUMAR A. Biodegradation of 2, 4-dichlorophenol by Bacillus endophyticus strain: optimization of experimental parameters using response surface methodology and kinetic study. Desalination and Water Treatment, 1, 2015.

29. MANIKANDAN K., VIRUTHAGIRI T. Kinetic and optimization studies on ethanol production from corn flour. International Journal of Chemical and Biological Engineering. 3 (2), 65, 2010.

30. MIRZA S.S., QAZI J.I., ZHAO Q., CHEN S. Photobiohydrogen production potential of Rhodobacter capsulatusPK from wheat straw. Biotechnology for biofuels.6(1), 144, 2013.

31. PLÁCIDO J., CAPAREDA S. Analysis of alkali ultrasonication pretreatment in bioethanol production from cotton gin trash using FT-IR spectroscopy and principal component analysis. Bioresources and Bioprocessing. 1 (1), $1,2014$.
32. SUCHY M., VIRTANEN J., KONTTURI E., VUORINEN T.Impact of drying on wood ultrastructure observed by deuterium exchange and photoacoustic FT-IR spectroscopy. Biomacromolecules. 11 (2), 515, 2009.

33. ZHAO X.B., WANG L., LIU D.H. Peracetic acid pretreatment of sugarcane bagasse for enzymatic hydrolysis: a continued work. J. Chemical Technology and Biotechnology. 83, 950, 2008.

34. IBRAHIM M.M., AGBLEVOR A.F., WALEED E. Isolation and characterization of cellulose and lignin from steam-exploded lignocellulosic biomass. BioResources. 5 (1), 397, 2010.

35. ROJITH G., SINGH I.S. Delignification, cellulose crystallinity change and surface modification of coir pith induced by oxidative delignification treatment. Int. J. Environ. Bioene. 3 (1), 46, 2012.

36. PLÁCIDO J., IMAM T., CAPAREDA S. Evaluation of ligninolytic enzymes, ultrasonication and liquid hot water as pretreatments for bioethanol production from cotton gin trash. Bioresource technology. 139, 203, 2013. 
